\title{
World Report on Disability, Intellectual Disabilities, and Disaster Preparedness: Costa Rica as a Case Example
}

\author{
Laura M. Stough \\ Texas A\&M University, College Station, TX, USA
}

\begin{abstract}
The World Report on Disability relates concerns about the experiences of individuals with intellectual disability in disaster situations. Disaster planning related to people with intellectual disability needs to consider that (1) they experience disproportionate risk in disaster situations, (2) they are often excluded from relief processes and are disadvantaged in disaster support situations, (3) they may need specialized disability-related supports, (4) they often have needs for assistive technology and special rehabilitative services, (5) family and community networks are important supports in disaster situations, and (6) during recovery, rebuilding should be inclusive and include disability needs. Thus, people with intellectual disabilities are more likely to need additional assistance during evacuation, experience more tangible losses during disaster, and require more intensive support in the recovery phase following disaster. Enabling access to mainstream systems and services, improving human resource capacity, and providing adequate funding for recovery and disaster mitigation are strategies to increase disaster resilience for individuals with intellectual disabilities. Costa Rica is one country that has designed emergency disaster management policies and incorporated disability rights policies that cut across governmental functions and promote interagency cooperation. Having such policy structures and legislative supports are advantageous for people with intellectual disability, whose support needs often cut across different functional areas.
\end{abstract}

Keywords: Costa Rica, Convention on the Rights of Persons with Disabilities, disaster, intellectual disability, preparedness

\section{Introduction}

The World Report on Disability (World Health Organization and World Bank, 2011) provides guidance on implementing the United Nations Convention on the Rights of Persons with Disabilities (CRPD) (United Nations, 2012) and highlights issues of concern for people with disability around the world. One of the main messages of the report is that disability disproportionally affects vulnerable populations. Specifically, disability prevalence is higher among women, the elderly, and those living in poverty and occurs at higher rates in poorer nations (World Health Organization and World Bank, 2011). People with intellectual disabilities are particularly and disproportionately disadvantaged in the world's poorest countries (Officer \& Shakespeare, 2013).

Similarly, disasters disproportionally affect vulnerable populations. Research on disasters reveals that women, the elderly, the poor, children, and individuals with disabilities are more likely

Received December 21, 2013; accepted December 11, 2014

Correspondence: Laura M. Stough, Department of Educational Psychology, Texas A\&M University, MS 4225, College Station, TX 77843 USA.

Tel: +1 979845 8257; E-mail: lstough@tamu.edu to be adversely affected by disasters than others (Norris et al., 2002; Peek \& Stough, 2010; Thomas, Phillips, Lovekamp, \& Fothergill, 2013). Disasters can also cause disabilities through injury or when healthcare services are disrupted following a disaster (International Federation of Red Cross and Red Crescent Societies, 2007; Wisner, 2002). As a result, at the intersection of disaster and disability, layered vulnerabilities and socioeconomic factors emerge that place individuals with disabilities at higher risk (Peek \& Stough, 2010; Phillips \& Morrow, 2007).

According to the United Nations International Strategy for Disaster Reduction (UN/ISDR), disasters are "a serious disruption of the functioning of a community or a society causing widespread human, material, economic, or environmental losses which exceed the coping capacity of the affected population" (2004, p. 17). Using this definition, a disaster may encompass natural causes, such as earthquakes and volcanic eruptions, as well as man-made causes, such as chemical spills, airplane crashes, and war. Indeed, the CRPD places war alongside natural disasters as risks that disproportionately affect people with disabilities. Further, armed conflict generates injuries that not only cause disability but also can complicate living with long-term disabilities (Ghobarah, Huth, \& Russett, 2004; World Health Organization and World Bank, 2011). Landmines, in particular, 
cause a high level of limb loss and traumatic brain injury (Ferguson, Richie, \& Gomez, 2004; Murray, King, Lopez, Tomijima, \& Krug, 2002). The CRPD addresses the safety and protection of persons with disabilities in disaster and conflict situations by noting that "states parties shall take, in accordance with their obligations under international law, including international humanitarian law and international human rights law, all necessary measures to ensure the protection and safety of persons with disabilities in situations of risk, including situations of armed conflict, humanitarian emergencies and the occurrence of natural disasters." (United Nations, 2012, Chapter 11).

While the World Report on Disabilities discusses the needs of people with disabilities in disasters, it does not specifically address those of people with intellectual disabilities. In this article, points are addressed which are raised in the World Report on Disabilities concerning disasters and disability and are related to specific concerns involving individuals with intellectual disabilities. Further, to illustrate how progressive policies can have supportive implications for people with intellectual disabilities affected by disaster or conflict, the country of Costa Rica is presented as an example.

\section{The World Report, Disasters, and Conflicts}

Following two introductory sections that discuss the conceptualization of disability and present a global picture of disability, the World Report on Disabilities summarizes the needs of individuals with disabilities in six areas. Some of these sections reference the impact of disasters or conflict as detailed below.

\section{Disability Prevalence}

According to the World Report on Disabilities the worldwide prevalence of disability is $15 \%$, higher than previously reported estimates. In addition, prevalence is increasing, primarily due to a global increase in chronic health conditions and the overall aging of the world population. Disability prevalence in specific countries is affected by environmental factors such as disasters, war, and pandemic illnesses. These catastrophic events not only increase impairment incidence in certain regions but may exacerbate medical conditions when disability-related health needs are not attended to appropriately (World Health Organization and World Bank, 2011). World estimates of intellectual disabilities vary from 1.5 to $2.5 \%$ of the world's population (Special Olympics, 2009). Disasters can increase the prevalence of intellectual disabilities through sudden-onset events that cause head trauma or anoxia, as well as through factors that affect cognitive development in fetuses or children, such as famine or infectious diseases. However, to date, no systemic review has been conducted on these causes.

The potential invisibility of people with intellectual disabilities sometimes means they do not receive cognitive supports required to cope with disaster contexts until those needs become critical and thus apparent to others. By comparison, individuals with visible disabilities or those who use visible supports, such as wheelchairs or guide dogs, or who use sign language, may obtain assistance more quickly as their needs can be more readily assessed by others. Further, Greenspan, Switzky, and Woods (2011) point out that individuals with intellectual disabilities display an unawareness of risk, both social and practical, and this characteristic can place them additionally at risk in disaster.

\section{Enabling Environments}

As discussed in the World Report on Disabilities, disasters and war not only cause disabilities but also create additional physical or communicational barriers in the environment. For example, fallen trees, torn up roads, or collapsed buildings make negotiating walkways and roads more difficult. Physical spaces that were previously accessible, such as schools or businesses, may no longer afford access in the postdisaster landscape. When critical information and communication technology is destroyed, it may be difficult to maintain and follow accessibility standards. During war or conflict periods, shelters and camps may not accommodate disability support needs. Noted specifically in the World Report on Disabilities are difficulties encountered by individuals on ventilators reliant on electrical power during evacuation. All of these situations can add to the difficulties that people with disabilities experience in the postdisaster milieu.

People with intellectual disabilities are likely to blend in when visual assessments are made in disaster shelters, delaying needed assistance when their needs are not identified by disaster workers. In addition, the postdisaster environment is usually in disarray and unfamiliar. People with intellectual disabilities who may have functioned independently prior to the disaster may need support in learning new pathways and routines when environmental changes occur. Need for support can be further aggravated when wars or natural disasters result in a high number of deaths and people with intellectual disabilities lose family members or others who formerly provided essential supports.

The World Report on Disabilities issued several specific recommendations regarding making environments resilient during disaster and conflict situations. First, it pointed out that universal design, wherein the built environment is designed to be equitably usable and accessible, serves an important role during emergency evacuations from buildings, noting that people with disabilities and the elderly are otherwise often left behind. Also, the report notes the importance of accessible technology and communications during disasters. Specifically, the World Report on Disabilities points out that countries with disability-related legislation that also have strong follow-up mechanisms to enforce such legislation achieve higher levels of universal access to information and communication technology. For example, Title II of the Americans with Disabilities (ADA) Amendments Act (2008) requires that emergency information conveyed through television or at public meetings be signed so as to be accessible for people who are deaf. Similarly, individuals with cognitive disabilities may need support in understanding evacuation-related informationduring emergencies. Although 
technology that supports cognitive disability needs is still in its infancy, legislation that increases technological accessibility is a first step toward equitable access.

\section{Rehabilitation}

The World Report on Disabilities defines rehabilitation as improving functioning so that people "achieve and maintain optimal functioning in interaction with their environment" (p. 96). The report specifically refers to the rehabilitation needs of people with disabilities following disasters and armed conflicts. For example, individuals may experience increased difficulties in navigating their environment due to fallen debris or barriers in roadways. Further, those directly affected by the disaster may need trauma care or psychological treatment quickly.

The World Report on Disabilities suggests that steps can be taken to mitigate deterioration in rehabilitation care postdisaster or postconflict. Detailed is the case of the state of Gujarat in India, which experienced an earthquake in 2001, killing some 18,000 and injuring 130,000 persons. The overall level of healthcare, particularly in the area of rehabilitation services for people with disabilities, was enhanced in a sustainable manner postdisaster through increased training and the integration of disability-related activity throughout the healthcare system. The case is an example of how successful postdisaster rehabilitation can be provided even in developing countries.

Although rehabilitation is usually considered for individuals with physical disabilities, individuals with intellectual disabilities are may also require rehabilitation services. Some estimates (e.g., Lin, Yen, Loh, Li, \& Wu, 2006) have found that that up to $24.5 \%$ of individuals with intellectual disabilities require rehabilitation services, including speech therapy, psychotherapy, occupational therapy, and physiotherapy. In addition, individuals with intellectual disabilities injured during disaster or conflicts will require rehabilitation services.

\section{Education}

Education is discussed in a subsection of the report on building teacher capacity and describes how the Inter-Agency Network on Education in Emergencies provides disaster information for teachers aiding students with disabilities in disaster situations. During the week, as children spend much of their days in school, and disasters may occur when they are apart from their parents, teachers may need to assume supervisory roles (Ducy \& Stough, 2011; Peek \& Stough, 2010). Students with disabilities may also require specialized support during evacuation, given mobility, health, or supervision needs.

Analyses of the literature on school emergency policies in some countries (see Boon, Pagliano, Brown, \& Tsey, 2012) have found that students with disabilities may be placed at risk or neglected during evacuations. In addition, disasters affect school buildings and may endanger children when safe building codes are not followed (Hewitt, 2007).

Children with intellectual disabilities make up 1-3\% of a given school population and will likely need assistance from their teachers and other school staff during disaster. A particular concern for these children following disaster is lost instructional time and the subsequent loss of academic skills (Ducy \& Stough, 2011). Further, when disasters affect the physical structures of day care centers, schools, or other educational institutions, they also disrupt the lives of teachers and others who staff them.

\section{Other Areas}

Although the World Report on Disabilities does not specifically address the role of disaster in the areas of general healthcare, assistance and support, or employment, the lives of people with intellectual disabilities are certainly affected by wars and disasters in those sectors. For example, healthcare facilities may be destroyed and doctors scarce, affecting access for people with intellectual disabilities with secondary health conditions. Assistance and support may be fragmented and less available when people with intellectual disabilities are separated from their care providers. In addition, employment, which is always a challenge for people with disabilities, is made more difficult when businesses are destroyed, struggling to recover, or when accessibility to them is temporarily limited.

\section{The Sphere Project}

In addition to the World Report, the CRPD (United Nations, 2012) has been particularly successful in influencing disabilityrelated disaster guidelines through The Sphere Project (Kett \& van Ommeren, 2009). The Sphere Project was developed by the International Red Cross and more than 400 nongovernmental organizations in 1997 in an effort to (1) improve efforts during disaster response and (2) create accountability for actions taken during disaster response. Citing the CRPD, Sphere acknowledges the particular needs of individuals with disabilities as a "crosscutting theme" across all sectors of disaster response (The Sphere Project, 2011). Sphere's philosophy is based on two core principles: (1) those affected by disaster or conflict have a right to life with dignity, and (2) all possible steps must be taken to alleviate human suffering arising out of disaster or conflict (The Sphere Project, 2013). The Sphere Project has published a handbook that identifies minimum standards in four areas of disaster response: water supply, sanitation, and hygiene promotion; food security and nutrition; shelter, settlement and nonfood items; and health action.

Several principles underlie the guidance of The Sphere Project's Handbook (2011) and align with those in the World Report. First, people with disabilities experience disproportionate risks in disaster situations, as evidenced by research and anecdotal reports. Second, people with disabilities are often excluded from relief and rehabilitation processes, which then makes it difficult for them to access and participate in disaster support services. Third, people with disabilities represent a diverse group; therefore, a blanket approach to disability-related supports should be avoided. Fourth, while people with disabilities have many of the same needs as other residents in the community, they may have specific needs for assistive technology and rehabilitative services. Fifth, family and community networks are particularly important for people with disabilities, and 
separation from these natural supports should be avoided in disaster situations. Finally, during the phases of recovery and mitigation communities should be rebuilt inclusively and for all sectors of the community. These recommendations intersect with policy recommendations in the World Report, particularly with respect to mainstreaming disaster-related services so that they are accessible to all. The Sphere recommendations do not, however, detail how to respond to the particular needs of individuals with intellectual disabilities postdisaster.

\section{Research on Disasters and Disability}

The World Report and The Sphere Project provide guidance and indicators for effective practices regarding people with disabilities in disaster. However, as has been previously noted regarding children and disaster standards (see Morris, Van Ommeren, Belfer, Saxena, \& Saraceno, 2007), practice has preceded systematic investigation, so most of these elements are based on expert opinion rather than empirical research. To a large part, this is because empirical studies on how disasters affect individuals with disabilities are limited (National Council on Disability, 2009; Peek \& Stough, 2010; Twigg, Kett, Bottomley, Tan, \& Nasreddin, 2011). As a result, commonsensical as many of these recommendations might appear, they may be applied without the requisite knowledge of and how they support people with disabilities.

Among existing studies, the primary focus has been on emergency preparedness and evacuation (Twigg et al., 2011). Some findings have revealed a significant difference between the level of preparedness of persons with disabilities and those without (e.g., Eisenman et al., 2009; Smith \& Notaro, 2009). Other researchers (e.g., Spence, Lachlan, Burke, \& Seeger, 2007; Uscher-Pines et al., 2009) have found that households with members with disabilities are less likely to plan for evacuation but are better prepared with respect to emergency supplies.

Evacuation behavior is clearly affected by disability status. For example, evacuation of households with people with disabilities has been found to take place at a lower rate and to be more delayed (see Van Willigen, Edwards, Edwards, \& Hessee, 2002), and family members often refuse to leave behind relatives who do not have accessible transportation (see Elder et al., 2007). A recent global survey sponsored by the United Nations revealed that only $20 \%$ of people with disabilities believed they could evacuate immediately and without difficulty in the face of a sudden-onset disaster (United Nations Office for Disaster Risk Reduction, 2013). People with physical disabilities are at a particular disadvantage during evacuations as the built environment usually does not accommodate those who cannot descend stairs, open doors, or quickly exit buildings (Christensen, Blair, \& Holt, 2007; Tierney, Petak, \& Hahn, 1988). Further, Murray (2011) noted that disaster preparedness personnel often do not consider the needs of children with disabilities or medical needs or when developing emergency evacuation plans and policies, making them even more vulnerable during disasters.

People with disabilities are also more tangibly affected by disaster. For example, households that include a family member with a disability in the United States are more likely to live in mobile homes and, as a result, experience significantly more damage to their homes during hurricanes than do other homeowners (Van Willigen et al., 2002). Mortality rates of people with disabilities are greater as well. In the Great East Japan tsunami, the mortality rate for people with disabilities was double that of the general population (Hisamatsu, 2013), and in the United States, the mortality rate was higher in frail older populations in Hurricanes Katrina and Rita (Aldrich \& Benson, 2008). War also can differentially target individuals with disabilities: In South Sudan, higher rates of exposure to traumatic events were reported by individuals with disabilities both during and after the armed conflict (Ayazi et al., 2013).

Finally, services for individuals with disabilities postdisaster differ. For example, emergency personnel and voluntary service organizations often fail to consider supports needed by individuals with disabilities in postdisaster exercises (Clive, Davis, Hansen, \& Mincin, 2010; Parr, 1987; Twigg, 2014). Similarly, Byrne and Davis (2005) found that volunteers using wheelchairs or portraying a visual impairment were passed over, ignored, or responded to inappropriately by emergency responders during a drill scenario. Sheltering postdisaster is also often inadequate for people with disabilities, evidencing problems such as barriers in physical entrance to shelters and the facilities within them, emergency communications that are not usable, and unequal access to disaster-related services (see Kailes, 2008; National Organization on Disability, 2005; Twigg et al., 2011; White, 2006). In addition, care providers of people with disabilities may be killed, injured, or diverted to other tasks, removing an important source of support for people with intellectual disabilities at a time of extraordinary need (World Health Organization, 2005).

\section{Intellectual Disabilities and Disaster}

Studies on how individuals with intellectual disabilities are impacted by disaster and conflict are even scarcer than those studies reviewed above. Some authors (e.g., Kett \& van Ommeren, 2009) suggest that individuals with cognitive impairments warrant priority in war and conflict situations as they are at high risk for abuse or early death. As individuals with intellectual disabilities evidence well-documented cognitive challenges in the areas of executive function, memory, and decision-making (see Alloway, 2010; Henry, Cornoldi, \& Mähler, 2010; Willner, Bailey, Parry, \& Dymond, 2010), it is probable they will need assistance in effectively responding to emergency situations.

The majority of studies conducted on preparedness training for people with intellectual disabilities have focused on teaching fire response, with few situations involving knowing what to do during earthquakes, tornados, or flooding (Dixon, Bergstrom, Smith, \& Tarbox, 2010). Dixon et al. (2010) concluded that interventions for preparing people with intellectual disabilities for emergency situations demonstrate varying degrees of generalization once training ceases. Rowland, White, Fox, and Rooney (2007) pointed out that specialized training for disaster responders is essential for working effectively with individuals with intellectual disabilities, but studies in this area have not been forthcoming.

With respect to evacuation, Shields, Smyth, Boyce, and Silcock (1999) examined the evacuation behaviors of people with intellectual disabilities who had received preparedness 
training in residential facilities in Ireland. During a nighttime drill, $80 \%$ of the 22 individuals studied responded to the alarm and were able to evacuate within $8 \mathrm{~min}$. However, the majority did not engage in other recommended evacuation behaviors, such as warning other residents, going to a safe refuge, or calling the fire department. Similar results were found by Scotti et al. (2007) who studied the responses to emergency events by 405 individuals with intellectual and developmental disabilities. More than $30 \%$ of their carers reported that these individuals became distressed during emergency situations and demonstrated stressed responses to emergency-related stimuli, such as sirens/bells (37\%), fire drills (22\%), flashing lights (22\%), strangers $(18 \%)$, and emergency personnel $(10 \%)$. What these findings imply is that signals typically used to communicate impending hazards may actually impede rather than support appropriate evacuation behaviors in individuals with intellectual disabilities.

In terms of postcrisis outcomes, Stough, Sharp, Decker, and Wilker (2010) conducted a long-term study of the recovery of 31 individuals with disabilities directly affected by Hurricane Katrina, which affected the United States. Seven of the participants or their family members had a cognitive disability and over half (a total of 16) reported having more than one disability. Six themes emerged as the most significant barriers to recovery: (1) housing, (2) transportation, (3) employment, (4) separation from family, (5) physical and mental health, and (6) accessing recovery services. Results suggested that disability status aggravated participants' negotiation of the disaster recovery process and made acquiring postdisaster resources more difficult.

In another study that focused on recovery, children with autism in Italy exposed to the L'Aquila earthquake, which left over 55,000 residents without housing, exhibited significant declines in their adaptive behavior in the first months after the event (Valenti et al., 2012). Specifically, significant declines were noted in communication, socialization, and other skills. Ducy and Stough (2011) similarly found children with intellectual disabilities exhibited decreases in behavioral, academic, and social skills following Hurricane Ike in the United States. In addition, children and their schools lost tangible resource items, such as wheelchairs, as well as accessible transportation, such as specially equipped buses or vans, necessary for them to attend class.

Although the studies summarized above are limited in sample size and in scope, they illustrate vulnerabilities that arise when individuals have difficulties in retaining information and in decision-making. Together with more general findings on disasters and disability, people with intellectual disabilities, regardless of the type of environmental hazard they encounter, are more likely to need additional assistance during evacuation, experience more tangible losses during disaster, and need additional support in the recovery phase following disaster.

\section{Country Context and Intellectual Disability}

The experiences of individuals with intellectual disabilities are distinguished by the context in which they occur. For example, in some developing countries, illiteracy and innumeracy may be common and thus limitations that many people with intellectual disabilities evidence in these areas do not attract attention. In addition, countries differ with respect to their geographical vulnerability to disasters, which, in turn, has different ramifications for people with disabilities. Finally, countryspecific emergency management policy and disability policy affect the extent to which people with disabilities are considered in disaster situations. It is critical, therefore, to consider the needs of individuals with intellectual disabilities within cultural context to understand policy effects. To provide an illustration of how intellectual disability, disaster, and emergency management policy intersect, the case example of Costa Rica is presented.

\section{The Case of Costa Rica}

Costa Rica is a mountainous Central American country bordered by Nicaragua to the north and Panama to the south. The Pacific Ocean lies along its western side and the Caribbean Sea to its east, together making up more than 900 miles of ocean coastline. The country encompasses just 19,730 square miles, smaller than the U.S. state of West Virginia. Two mountain ranges run north to south and two thirds of the country's total population of 4.8 million people live between these ranges. The climate is tropical and humid, with two seasons, a long rainy season and a shorter dry season. As a result, lush vegetation and a wide diversity of plant and animal species exist within the borders of the country (Biesanz, Biesanz, \& Biesanz, 1999).

Costa Rica has experienced a primarily peaceful existence as a governmental democracy since 1839. A brief civil war broke out in 1948, after which Costa Rica drafted a new constitution, democratically elected a new government and head of state, and abolished its military (Helmuth, 2000). The country has remained politically stable ever since, primarily under the governance of two political parties. As it does not support a military force, it has proportionately more available funds for social investment than do other countries. The World Bank (2013) considers Costa Rica a middle-income country, as it has an average per capita yearly income of US\$ 9,391.

A number of socially progressive programs form the bedrock of Costa Rican stability, including universal healthcare, support for mothers and young children, and a public transportation system (Biesanz et al., 1999; Stough, 2003). Approximately 23\% of the national budget is dedicated to a constitutionally provisioned free public education (United Nations Educational, Scientific and Cultural Organization [UNESCO], 2011), and schools are constructed and staffed even in the most isolated regions of the country (Stough, 2002; Stough \& Aguirre-Roy, 1997).

Costa Rica and disasters. Costa Rica is exposed to numerous natural hazards, including earthquakes, floods, hurricanes, landslides, and volcanic eruptions, and is ranked second among countries most exposed to multiple hazards based on land area (The World Bank, 2013). An estimated 77.9\% of Costa's Rica's total population resides in high risk areas that are exposed to multiple hazards (Dilley et al., 2005). The country is also one of the most earthquake-prone and volcanically active countries in the world as it lies on two main tectonic plates; in fact, 9 of its 16 volcanoes are currently active (The World Bank, 2013). Storms 
and floods affect a large number of people and a rise in flood loss and damage in the last several decades has been noted (Hori \& Shaw, 2013). Further, drought occasionally occurs in the western provinces, causing loss to agriculture and cattle production.

Between 1980 and 2008 more than 800,000 residents, approximately one fifth of the population, were affected by earthquakes, storms, floods, or drought (The World Bank, 2013). While most hurricanes do not make landfall in Costa Rica, they sometimes cause strong tropical storms (Afedzie, McEntire, \& Urby, 2010); for example, Hurricane Mitch caused economic damage of more than US\$ 98 million in Costa Rica.

Studies suggest that there is a trend toward increased variability in temperature and precipitation patterns, particularly in the last decade (The World Bank, 2013), with subsequent economic losses increasing from climate-related events (Hori \& Shaw, 2011). In the 49 disasters that occurred in Costa Rica in the last 30 years, 2 million people were affected, 353 deaths occurred, and the economic cost was over US\$ 2.06 billion (Centre for Research on the Epidemiology of Disasters [CRED], 2013).

Challenges and risks. One of the biggest challenges for emergency management in Costa Rica is the pattern of population growth. Growth is occurring most rapidly in the Central Valley, largely due to the concentration of employment opportunities. As the Central Valley is also the most populous part of the country, buildings are increasingly constructed on steep mountainsides and along river basins. A lack of affordable housing leads low-income families to seek housing in higher risk areas lying in flood plains or that are more susceptible to earthquake damage. In addition, the substantial rainfall that occurs during the rainy season in Costa Rica and subsequent landslides can destabilize the foundations of poorly constructed houses.

Many communities in Costa Rica are located along steep ravines or on mountainsides accessible only via ground and usually have only a single route of egress, making evacuation routes vulnerable. Given the mountainous terrain, roads in Costa Rica are also vulnerable to landslides caused by storms, flooding, or earthquakes. In addition, development is encroaching upon volcanic areas (Afedzie et al., 2010), which are more seismically active. Air infrastructure, for example, helicopters, small airplanes, and airstrips, is limited. As a result, regions of the country may become completely inaccessible following a disaster for several days or even weeks.

Costa Rica's burgeoning tourism industry, which supplies one of the highest sources of foreign income for the country, has created new vulnerabilities. For example, large tourist hotels have sprung up along the western Nicoya peninsula, which is vulnerable to storms and flooding and also lies over a major earthquake fault. In September of 2012, when a massive 7.6 earthquake struck along this fault line, only the depth of the rupture, at 24 miles, prevented widespread death and destruction. Other popular tourist destinations are located near active volcanoes, in mountain communities that have limited egress, or in the aforementioned Central Valley. These tourist locations are reliant on local business infrastructure as well as housing constructed for employees, meaning that a larger segment of the native Costa Rican population is also exposed to hazards in these areas.

Hazards and intellectual disabilities. These three major challenges for emergency management in Costa Rica-the pattern of population growth, the vulnerability of the transportation system, and the increasing tourism sector-have distinct ramifications for people with intellectual disabilities. Emerson (2007) notes that people with intellectual disabilities are more likely to live in poverty, which negatively affects the quality of housing in which they live. Further, Tierney et al. (1988) point out that individuals with disabilities are more likely to live in older buildings. Although no studies have been conducted in this area to date, it is reasonable to assume that individuals with intellectual disabilities in Costa Rica are also at increased risk for exposure to the hazards that affect substandard housing. In addition, Costa Rica has never had a tradition of housing people with disabilities in institutions, so people with intellectual disabilities live in the community like others in the general population. While this means that housing and social supports are normalized, it also means that people with intellectual disabilities are at risk for hazards at the same rate as those without disabilities. Further, when evacuation routes are cut off, individuals with medical conditions related to their intellectual disabilities may experience secondary health concerns or even secondary disabilities as a result of interruption in medical care or delayed medication. In addition, as more Costa Rican families move into hazardous locations serving the tourism industry, the more likely their family members with disabilities similarly will be placed at risk.

Policies of benefit to individuals with intellectual disabilities. Costa Rica has emergency management and disability policies in place likely of benefit to individuals with intellectual disabilities and their families during disaster. The World Bank (2013) noted that Costa Rica "has made substantial progress in its institutional and legal framework" (p. 1) regarding managing disaster risk. The National System for Disaster Risk Management (SNPRAE), established by legislative amendment in 2006, guides the function of the National Emergency Commission (CNE), which is the lead institution for emergency planning, management, and hazard reduction in Costa Rica. SNPRAE serves a cross-cutting function in that it mandates that all public institutions consider disaster management in their planning and organization. Thus, designated staff within various ministries (the Department of Health, the Department of Transportation, etc.) are appointed as functionaries as part of the emergency management system. By affecting multiple agencies, SNPRAE increases safeguards for individuals with disabilities as it moves the responsibilities for addressing the needs of the community away from a centralized function within a single agency.

A similar cross-agency function is used to implement crossagency collaboration as a result of strong disability policy legislation. The Equal Opportunity Law for Persons with Disabilities, passed in 1996, guarantees equal rights for individuals with disabilities across all sectors of public life, including equal access to work, health services, transportation, communication services, as well as to cultural, sport, and recreational activities and 
includes anti-discriminatory disability clauses (Stough, 2003). In addition, this progressive legislation covers both the private and the public sectors as part of its directives.

Although Costa Rica, due to economic limitations, has historically turned to international institutions and foreign donors for assistance following major disasters, significant policy initiatives have been undertaken to integrate disaster risk reduction into the National Emergency Commission established in 1986 (Afedzie et al., 2010). Profits and financial surplus from governmental institutions are transferred to the National Emergency Fund, and all agencies must allocate resources to disaster preparation in their budgets (Afedzie et al., 2010). In addition, the Catastrophe Deferred Drawdown (Cat DDO), a form of contingent financing offered through The World Bank, provides funding to member countries in the event of a natural disaster (The World Bank, 2013). In 2009, Costa Rica became the first country to benefit from a Cat DDO loan when an earthquake struck 20 miles north of San José, the capital of the country.

The World Report and disaster in Costa Rica. Although the specific needs of individuals with intellectual disabilities experiencing disaster or conflict are not detailed in the World Report, many of the report's general recommendations seem applicable in the case of Costa Rica: enabling access to mainstream systems and services, improving human resource capacity, and providing adequate funding for recovery and disaster mitigation. Costa Rica provides a relevant case study in that both emergency management policies and disability rights policies have been designed to cut across different governmental functions and promote interagency cooperation. Such a structure is advantageous for people with intellectual disabilities as their support needs similarly cut across different areas, including transportation, employment, education, housing, and so on.

Overall, Costa Rica serves as a positive case example as it has "developed the most comprehensive legal and institutional disaster risk management frameworks in the Central American Region" (Global Facility for Disaster Reduction and Recovery, 2013, p. 1) as well as a funding mechanism that anticipates the need for economic support during disaster. Finally, Costa Rica has not engaged in a significant conflict for over 70 years, thus eliminating war as a cause of disability.

However, as noted in the World Report on Disabilities, proper implementation of legislation relies on the mechanisms created to ensure carry-through. Although Costa Rica has passed progressive legislation that addresses the needs of individuals with disabilities, too often implementation and enforcement are lacking. Sadly, without consistent enforcement, even otherwise progressive policies are reduced to rhetoric. For example, Costa Rica has passed excellent building codes for seismically resistant construction; however, private property owners often skirt these codes, placing buildings and those who live or work in them at risk. Similarly, public transportation systems in Costa Rica have been obligated to be accessible to people who use wheelchairs since 1996; however, only recently have buses been placed in service that accommodate wheelchairs in the capital city. In addition, while disability expertise has steadily increased through advanced training in the areas of special education and rehabilitation, such expertise tends to be concentrated in the
Central Valley, with considerable needs for such expertise remaining in the outlying rural provinces.

\section{Conclusion}

The World Report on Disabilities points out the overall lack of research on disability and the critical need for data-based studies to inform policy. Research is similarly lacking on the effect of disasters on individuals with intellectual disabilities. While this article has summarized the few existing studies and reviews on how individuals with disabilities fare in the event of disaster and conflict, we need more research about and illustrations of how individuals with disabilities overcome barriers created by these situations (Cohen \& Brown, 2012). In the words of Bickenbach (2011), the aspirations of the CRPD can only be achieved by "solid evidence, good science, and sound scholarship; political rhetoric and slogans, although they have their role, are not enough" (p. 658).

Finally, at the panel on Disaster Resilience and Disability held in observance of the 2013 International Day of Disaster Reduction, Ambassador H. E. Khan of Indonesia stated, "disability increases vulnerability but disability is not inability" (2013; p. 8). People with disabilities, including those with intellectual disabilities, can participate in reducing their own vulnerability to disasters. And, when the vulnerability of one segment of the population is addressed, the resilience of the entire community is increased. Full participation of individuals with intellectual disabilities, both in the delivery of disaster-related services and in the planning of them, not only creates better-designed preparation for disasters, it increases social inclusion. People with intellectual disabilities can participate in planning for and responding to disasters. However, first, they must be included in such planning and response.

\section{References}

Afedzie, R., McEntire, D. A., \& Urby, H. (2010). Emergency management in Costa Rica: A unique model for developing and developed nations. In D. McEntire, D. B. Aguirre, R. Afedzie, D. Alqusairi, V. Bai, C. Bong, \& M. Zannoni (Eds.), Comparative emergency management: Understanding disaster policies, organizations, and initiatives from around the world (pp. 1-14). Emmitsburg, MD: Federal Emergency Management Agency. Retrieved from http://training.fema .gov/hiedu/downloads/compemmgmtbookproject/ comparative $\% 20$ em $\% 20$ book $\% 20-\% 20$ chapter $\% 20$ $\% 20$ emergency $\% 20$ management $\% 20$ in $\% 20$ costa $\% 20$ rica.doc

Aldrich, N., \& Benson, W. F. (2008). Disaster preparedness and the chronic disease needs of vulnerable older adults. Preventing Chronic Disease, 5, A27.

Alloway, T. P. (2010). Working memory and executive function profiles of individuals with borderline intellectual functioning. Journal of Intellectual Disability Research, 54, 448-456.

ADA Amendments Act of 2008. (2008). An act to restore the intent and protections of the Americans with Disabilities Act of 1990, Public Law 110-325. Retrieved from http://www.eeoc.gov/laws/statutes/ adaaa.cfm

Ayazi, T., Lien, L., Eide, A. H., Jenkins, R., Albino, R. A., \& Hauff, E. (2013). Disability associated with exposure to traumatic events: Results from a cross-sectional community survey in South Sudan. BMC Public Health, 13, 469. 
Bickenbach, J. (2011). The world report on disability. Disability \& Society, 26, 655-658. doi: 10.1080/09687599.2011.589198

Biesanz, M. H., Biesanz, R., \& Biesanz, K. Z. (1999). The Ticos: Culture and social change in Costa Rica. Boulder, CO: Lynne Rienner.

Boon, H. J., Pagliano, P., Brown, L., \& Tsey, K. (2012). An assessment of policies guiding school emergency disaster management for students with disabilities in Australia. Journal of Policy and Practice in Intellectual Disabilities, 9, 17-26.

Byrne, M., \& Davis, E. A. (2005). Preparedness for all, why including people with disabilities in drills is a learning tool: Interagency Chemical Exercise (I.C.E.). IAEM Bulletin, 7-8/14.

Centre for Research on the Epidemiology of Disasters (CRED). (2013). EM-DAT (Emergency Events Data Base). The international disaster database. Brussels, Belgium: Ecole de Santé Publique, Université Catholique de Louvain. Retrieved from http://www.em-dat.net/ index.htm

Christensen, K. M., Blair, M. E., \& Holt, J. M. (2007). The built environment, evacuations, and individuals with disabilities: A guiding framework for disaster policy and preparation. Journal of Disability Policy Studies, 17, 249-253.

Clive, A., Davis, E. A., Hansen, R., \& Mincin, J. (2010). Disability. In B. Phillips, S. Thomas, A. Fothergill, \& I. Blinn-Pyke (Eds.), Social vulnerability to disasters (pp. 187-216). Boca Raton, FL: CRC Press.

Cohen, L., \& Brown, R. I. (2012). Mapping future research in disabilities-Research initiatives in intellectual disabilities in India: Report of a national interdisciplinary meeting. Journal of Policy and Practice in Intellectual Disabilities, 9, 151-155.

Dilley, M., Chen, R.S., Deichmann, U., Lerner-Lam, A. L., \& Arnold, M., with Agwe J. . . \& Yetman, G. (2005). Natural disaster hotspots: A global risk analysis (Vol. 5). Washington, DC: The World Bank.

Dixon, D. R., Bergstrom, R., Smith, M. N., \& Tarbox, J. (2010). A review of research on procedures for teaching safety skills to persons with developmental disabilities. Research in Developmental Disabilities, 31, 985-994.

Ducy, E. M., \& Stough, L. M. (2011). Exploring the support role of special education teachers after Hurricane Ike: Children with significant disabilities. Journal of Family Issues, 32, 1325-1345. doi: 10.1177/0192513X11412494

Eisenman, D. P., Zhou, Q., Ong, M., Asch, S., Glik, D., \& Long, A. (2009). Variations in disaster preparedness by mental health, perceived general health, and disability status. Disaster Medicine and Public Health Preparedness, 3, 33-41.

Elder, K., Xirasagar, S., Miller, N., Bowen, S. A., Glover, S., \& Piper, C. (2007). African Americans' decisions not to evacuate New Orleans before Hurricane Katrina: A qualitative study. American Journal of Public Health, 97(Suppl. 1), S124-S129.

Emerson, E. (2007). Poverty and people with intellectual disabilities. Mental Retardation and Developmental Disabilities Research Reviews, 13, 107-113.

Ferguson, A. D., Richie, B. S., \& Gomez, M. J. (2004). Psychological factors after traumatic amputation in landmine survivors: Between physical healing and full recovery. Disability and Rehabilitation, 26, 931-938.

Ghobarah, H. A., Huth, P., \& Russett, B. (2004). The post-war public health effect of civil conflict. Social Science \& Medicine, 59, 869-884.

Global Facility for Disaster Reduction and Recovery. (2013, May). Country program update: Costa Rica. Retrieved from http:// www.gfdrr.org/sites/gfdrr.org/files/CostaRica.pdf

Greenspan, S., Switzky, H. N., \& Woods, G. W. (2011). Intelligence involves risk-awareness and intellectual disability involves riskunawareness: Implications of a theory of common sense. Journal of Intellectual and Developmental Disability, 36, 242-253. doi: 10.3109/ 13668250.2011 .626759

Helmuth, C. (2000). Culture and customs of Costa Rica. Westport, CT: Greenwood Press.
Henry, L., Cornoldi, C., \& Mähler, C. (2010). Special issues on "working memory and executive functioning in individuals with intellectual disabilities." Journal of Intellectual Disability Research, 54, 293-294. doi: $10.1111 /$ j.1365-2788.2010.01266.x

Hewitt, K. (2007). Preventable disasters: Addressing social vulnerability, institutional risk, and civil ethics. Geographischs Rundschau International Edition, 3, 43-52.

Hisamatsu, M. (2013). Panel discussion on disaster resilience and disability: Ensuring equality and inclusion. Co-organized by UNDESA, UNISER in collaboration with Indonesia and Norway and the Nippon Foundation. New York, NY: UN Headquarters.

Hori, T., \& Shaw, R. (2011). Incorporation of potential climate change impacts into local disaster risk management in Costa Rica. Risk, Hazards \& Crisis in Public Policy, 2, 1-30.

Hori, T., \& Shaw, R. (2013). Global climate change perception, local risk awareness, and community disaster risk reduction: A case study of Cartago City, Costa Rica. Risk, Hazards \& Crisis in Public Policy, 3, $77-104$.

International Federation of Red Cross and Red Crescent Societies. (2007). World disasters report: Focus on discrimination. Satigny/ Verner, Switzerland: ATAR Roto Presse.

Kailes, J. (2008). Southern California wildfires after action report. Pomona, CA: Access to Readiness Coalition, The California Foundation for Independent Living Centers, and The Center for Disability Issues and the Health Professions at Western University of Health Sciences. Retrieved from http://www.jik.com/CaliforniaWildfires.pdf

Kett, M., \& van Ommeren, M. (2009). Disability, conflict, and emergencies. Lancet, 274, 1801-1803.

Khan, H. E. (2013, October). In M. Wahlström (Chair), IDRR panel discussion: Disaster resilience and disability-Ensuring equality and inclusion. Panel presented by UNISDR, UN DESA, The Permanent Missions of Indonesia \& Norway to the United Nations, and the Department of Economic and Social Affairs, New York, NY.

Lin, J. D., Yen, C. F., Loh, C. H., Li, C. W., \& Wu, J. L. (2006). Rehabilitation service utilization and determinants among people with an intellectual disability: Preliminary findings in Taiwan. Disability and Rehabilitation, 28, 1499-1506.

Morris, J., Van Ommeren, M., Belfer, M., Saxena, S., \& Saraceno, B. (2007). Children and the Sphere standard on mental and social aspects of health. Disasters, 31, 71-90.

Murray, C. J. L., King, G., Lopez, A. D., Tomijima, N., \& Krug, E. J. (2002). Armed conflict as a public health problem. British Medical Journal, 324, 346-349.

Murray, J. S. (2011). Disaster preparedness for children with special healthcare needs and disabilities. Journal for Specialists in Pediatric Nursing, 16, 226-232.

National Council on Disability. (2009). Effective emergency management: Making improvements for communities and people with disabilities. Retrieved from http://www.ncd.gov/policy/emergency_management

National Organization on Disability. (2005). Report on special needs assessment for Karina evacuees (SNAKE) project. Washington, DC: Author. Retrieved from http://www.nod.org/Resources/PDF/ katrina_snake_report.pdf

Norris, F. H., Friedman, M. J., Watson, P. J., Byrne, C. M., Diaz, E., \& Kaniasty, K. (2002). 60,000 disaster victims speak: Part I. An empirical review of the empirical literature, 1981-2001. Psychiatry, 65, 207-239.

Officer, A., \& Shakespeare, T. (2013). The World Report on disability and people with intellectual disabilities. Journal of Policy and Practice in Intellectual Disabilities, 10, 86-88.

Parr, A. R. (1987). Disasters and disabled persons: An examination of the safety needs of a neglected minority. Disasters, 11, 148-159.

Peek, L., \& Stough, L. M. (2010). Children with disabilities in the context of disaster: A social vulnerability perspective. Child Development, 81, 1260-1270. 
Phillips, B. D., \& Morrow, B. H. (2007). Social science research needs: Focus on vulnerable populations, forecasting, and warnings. Natural Hazards Review, 8, 61-68.

Rowland, J. L., White, G. W., Fox, M. H., \& Rooney, C. (2007). Emergency response training practices for people with disabilities. Journal of Disability Policy Studies, 17, 216-222.

Scotti, J. R., Stevens, S., Cavender, A., Morford, M., Jacoby, V., Freed, R., \& Burkhart, S. (2007, November). Response of persons with mental retardation/developmental disabilities to emergency situations: Implications for disaster preparedness. Presentation at the 23rd annual meeting of the International Society for Traumatic Stress Studies, Baltimore, MD.

Shields, T. J., Smyth, B., Boyce, K. E., \& Silcock, G. W. H. (1999). Evacuation behaviours of occupants with learning difficulties in residential homes. Disability and Rehabilitation, 21, 39-48.

Smith, D. L., \& Notaro, S. J. (2009). Personal emergency preparedness for people with disabilities from the 2006-2007 behavioral risk factor surveillance system. Disability and Health Journal, 2, 86-94.

Special Olympics. (2009). Status and prospects of persons with intellectual disabilities. Retrieved from http://www.specialolympics.org/ uploadedFiles/LandingPage/WhatWeDo/Research_Studies _Desciption_Pages/Policy_Paper_Status_Prospects.pdf

Spence, P. R., Lachlan, K., Burke, J. M., \& Seeger, M. W. (2007). Media use and information needs of the disabled during a natural disaster. Journal of Health Care for the Poor and Underserved, 18, 394-404.

Stough, L. M. (2002). Teaching special education in Costa Rica. Teaching Exceptional Children, 34, 34-39.

Stough, L. M. (2003). Special education and severe disabilities in Costa Rica: Developing inclusion in a developing country. Research and Practice for Persons with Severe Disabilities: The Journal of TASH, 28, 7-15.

Stough, L. M., \& Aguirre-Roy, A. R. (1997). Learning disabilities in Costa Rica: Challenges for "an army of teachers." Journal of Learning Disabilities, 30, 566-571.

Stough, L. M., Sharp, A. N., Decker, C., \& Wilker, N. (2010). Disaster case management and individuals with disabilities. Rehabilitation Psychology, 55, 211-220. doi: 10.1037/a0020079

The Sphere Project. (2011). The Sphere project: Humanitarian charter and minimum standards in disaster response. Dunsmore, UK: Practical Action Publishing. Retrieved from http://www.sphereproject.org/ resources/download-publications/?search=1\&keywords=\&language $=$ English\&category $=22$

The Sphere Project. (2013). The Sphere Project. What is Sphere? Retrieved from http://www.spherehandbook.org/en/what-is-sphere/

The World Bank. (2013). Disaster risk management in Central America: Global facility for disaster reduction and recovery country notes. Costa Rica. Washington, DC: Author. Retrieved from http://www.gfdrr .org/sites/gfdrr.org/files/Costa_Rica_DRM.pdf

Thomas, D. K., Phillips, B. D., Lovekamp, W. E., \& Fothergill, A. (2013). Social vulnerability to disasters (2nd ed.). Boca Raton, FL: CRC Press.
Tierney, K. J., Petak, W. J., \& Hahn, H. (1988). Disabled persons and earthquake hazards. Boulder, CO: Institute for Social and Behavioral Science, Natural Hazards Research and Applications Information Center.

Twigg, J. (2014). Attitude before method: Disability in vulnerability and capacity assessment. Disasters, 38, 465-482.

Twigg, J., Kett, M., Bottomley, H., Tan, L. T., \& Nasreddin, H. (2011). Disability and public shelter in emergencies. Environmental Hazards, 10, 248-261.

United Nations. Conference of States Parties to the Convention on the Rights of Persons with Disabilities. (2012, September). Convention on the rights of persons with disabilities. Retrieved from http:// www.un.org/disabilities/convention/conventionfull.shtml

United Nations Educational, Scientific and Cultural Organization [UNESCO]. (2011). UNESCO Institute for Statistics, Statistics in brief, Costa Rica profile. Retrieved from http://stats.uis.unesco.org/ unesco/TableViewer/document.aspx?ReportId=121\&IF_Language $=$ eng $\&$ BR_Country $=1880 \&$ BR_Region $=40520$

United Nations International Strategy for Disaster Reduction. (2004). Living with risk: A global review of disaster reduction (Vol. 1). New York, NY, and Geneva, Switzerland: United Nations.

United Nations Office for Disaster Risk Reduction [UNISDR]. (2013). UN global survey explains why so many people living with disabilities die in disasters. Retrieved from http://www.unisdr.org/archive/35032

Uscher-Pines, L., Hausman, A. J., Powell, S., DeMara, P., Heake, G., \& Hagen, M. G. (2009). Disaster preparedness of households with special needs in southeastern Pennsylvania. American Journal of Preventive Medicine, 37, 227-230.

Valenti, M., Ciprietti, T., Di Egidio, C., Gabrielli, M., Masedu, F., Tomassini, A. R., \& Sorge, G. (2012). Adaptive response of children and adolescents with autism to the 2009 Earthquake in L'Aquila, Italy. Journal of Autism and Developmental Disorders, 42, 954-960.

Van Willigen, M., Edwards, T., Edwards, B., \& Hessee, S. (2002). Riding out the storm: Experiences of the physically disabled during Hurricanes Bonnie, Dennis, and Floyd. Natural Hazards Review, 3, 98-106.

White, B. (2006). Disaster relief for deaf persons: Lessons from hurricanes Katrina and Rita. The Review of Disability Studies, 2, 49-56.

Willner, P. P., Bailey, R. R., Parry, R. R., \& Dymond, S. S. (2010). Evaluation of the ability of people with intellectual disabilities to "weigh up" information in two tests of financial reasoning. Journal of Intellectual Disability Research, 54, 380-391. doi: 10.1111/j.13652788.2010.01260.x

Wisner, B. (2002). Disability and disaster: Victimhood and agency in earthquake risk reduction. Retrieved from http://www.radixonline .org/resources/disability_and_disaster_wisner.doc

World Health Organization. (2005). Disasters, disability and rehabilitation. Retrieved from http://www.who.int/violence_injury _prevention/other_injury/disaster_disability2.pdf

World Health Organization, \& World Bank. (2011). World report on disability. Retrieved from http://www.who.int/disabilities/world _report/2011/en/index.html 